\title{
"STANDING CROP" NA ÁREA ESTUARINA SW DA BAYA DE TODOS OS SANTOS *
}

\author{
VERA MARIA CARVALHO PEIXINHO \\ JORGE FALCĀO PAREDES
}

ELIANA MARIA PALMA SIMAS

Instituto de Biologia, Universidade Federal da Bahia. Salvador, BA, Brasil

\section{SYNOPSIS}

The present study is mtended to evaluate the potential of an estuarine area surrounded by mangrove at Todos os Santos Bay (Bahia Sta. te, Brazil), for supporting aquaculture activities. From October 1977 to July 1978 samples were collected monthly on alternate tides for de. termination of Darticulate organic carbon and total proteins. The following environmental parameters were also considered: salinity. temperatu$r e, p H$, transparence, dissolved oxygen, silicates, ammonia, nitrites, nitrates, phosphates and precipitation. Although the area presented low cell density and low photossinthetic activity, high values for the standing crop were found, demonstrating the importance of detritic material for
the particulate organic matter.

\section{Introdução}

E amplamente difundido o conceito de que as águas estuarinas são mais produtivas que o mar aberto, sendo capazes de uma produção de matéria orgânica a uma taxa anual de 10 a 100 vezes maior aue as águas oceânicas (Perkins. 1974)

A Baía de Todos os Santos $\left(13^{\circ} 00^{\prime} \mathrm{S}\right.$ e $38^{\circ} 30^{\prime} \mathrm{W}$ ) com $800 \mathrm{~km}^{2}$ de extensão, representa uma bacia naturalmente relevante em termos de produção, embora muito pouco explorada quanto ao conhecimento do seu real potencial. Nela desembocam 5 estuários, todos eles marginados por extensas áreas de manguesais que contribuem naturalmente com elevados teores de matéria orgânica detrítica para as águas estuarinas.

Nossos estudos concentram-se nos estuarios dos nos Jaguaripe e Jacuruna, localizados à sudoestes da Baía de Todos os Santos, área de elevada precipitação pluviométrica (2000/2300 $\mathrm{mm}$ anuais), onde se desenvolvem estudos de biologia básica e prática de cultivo da ostra nativa do mangue Crassostrea rizophorae.

A quantificação sazonal da biomassa em termos de carbono e proteínas particulados é analisada e discutida, relacionada à parâmetros ambientais físico-químicos e meteorológicos.

\section{Metodologia}

1 - Amostragens - Foram realizadas mensalmente no período de outubro de 1977 a julho de 1978, nos cursos da enchente e da vazante, em 4 estações, sendo 2 situadas no Rio Jacuruna, uma no Rio Jaguaripe e uma no Canal de Itaparica, onde desembocam os dois estuários (Fig. 1) As tomadas de águas foram feitas por bomba elétrica submersível, em superfície e fundo, ou simplesmente à profundidade do disco de Secchi para carbono e proteínas. Nas estaçōes de pouca profundidade $(0$ e 1$)$ essas amostragens realizaram-se em apenas 1 nível.

2 - Salinidade e temperatura - Dada por salinômetro - termômetro condutivímetro seckman.

3 - $p H$ - Determinações potenciométricas com medidor $\mathrm{Hel}$ lige Lilliput mod. 750.

4 - Transparência - Dada por disco de Secchi $(30 \mathrm{~cm})$.

5 - Oxigênio dissolvido - Método titulométrico de Winkler de acordo com a padronização de Magliocca (1966).

6 - Amônia - Análise colorimétrica segundo método modificado e descrito em Strickland \& Parsons (1972).

7 - Nitratos e nitritos - Método colorimétrico da redução dos nitratos a nitritos em coluna de cobre e cadmio de acordo com a descrição de Strickland \& Parsons (1972).

8 - Fosfatos - Métodos de Murphy e Riley de acordo com as modificaçōes de Koroleff (Grasshof, 1976).

9 - Silicatos-De acordo com o método colorimétrico descrito em Strickland \& Parsons (1972).

10 - Matéria orgânica e inorgânica em suspensão - Detritos concentrados em membrana GF de $47 \mathrm{~mm} \phi$ e oxidados em $500^{\circ} \mathrm{C}$; frações orgânicas e inorgânicas calculadas por diferença de peso seco.

11 - Carbono particulado - Por oxidação úmida segundo o método descrito por Johnson e referido em Strickland \& Parsons (1972)

12 - Protelnas da matéria particulada - Concentração da matéria em membrana GF de $25 \mathrm{~mm} \phi$ e proteínas quantificadas pelo método de Lowry, modificado por Price (1965).

13 - Correntes de superficie - Medidas com flutuador "tipo cogumelo" cronometrado em percurso padrão.
14 - Precipitação - Determinada por pluviômetro instalado nas proximidades da estação 1 .

Resultados

1 - Parámetros meteorológicos e físico-químicos - A área estudada situa-se na faixa de mais alta pluviosidade de recôncavo da Bahia, com totais anuais de 2200 a $2300 \mathrm{~mm}$ normalmente concentrados no período compreendido entre março e agosto, definindo uma época chuvosa e uma época seca compreendendo o período de setembro a fevereiro. Na Figura 2 a pluviosidade registrada na estação 1 , de março 77 a março de 78 , evidencia esta situação com um pico excepcional em outubro.

$\mathrm{O} \mathrm{pH}$ apresenta grandes flutuações mais evidentes nas estações do rio Jacuruna onde atinge valores de até 5,2 nas épocas de maior pluviosidade, quando a intensa drenagem do solo do manguesal carreando ácidos húmicos e tânicos provoca uma acidificação das águas.

Nas estações $2 \mathrm{~A}$ e 4 , que sofrem a maior influência marinha, este parâmetro se apresenta bem mais estável (Tab. I).

As temperaturas registradas nesse periodo (Tab. II) mostraram pequenas variações relativamente às 4 estações ma. revelam uma variação sazonal com valores mínimos registrados nas épocas de maior pluviosidade. As estações mais rasas $(0 \mathrm{e} 1)$ apresentam maiores flutuações, por serem mais sensíveis às variaçōes de insolação e precipitação. Nas estações mais profundas ( $2 \mathrm{~A}$ e 4) a amplitude de variação sazonal é menor e nẫo se observa estratificacão

Jả a salınıđade revela ligeira estratiticaçấo na estação 4 . mais evidente no mês de outubro (Fig. 3 ). Este parämetro apresenta-se como variável de pequena amplitude nas estações $2 \mathrm{~A}$ e 4 com médias anuais em torno de 30 a $28 \%$ oo, respectivamente, confirmando a maior influência marinha nessas duas estações. A ausência de estratificação na estação $2 \mathrm{~A}$, evidencia $\mathrm{O}$ alto grau de mistura nas águas do Canal de Itaparica. Nas estações 0 e 1 a salinidade mostra variações de grande amplitude, sazonais e entre-marés, com valores médios de 10 a $25 \%$ oo, respectivamente.

A taxa de saturação do $\mathrm{DO}$ nas estações $1,2 \mathrm{~A}$ e 4 , raramente decaiu abaixo de $70 \%$ (Fig. 4). No entanto, na estaçâo 0 esta taxa ocorreu com certa frequêencia abaixo de $70 \%$, principalmente durante a vazante. Idêntica situação foi constatada em duas observaçōes na estação $1 \mathrm{e}$, em uma única, na estação 4 . As situaçōes mais críticas têm sua ocorrência nos meses de fevereiro (estação 0 e 1) e em maio, com reflexos em todas as 4 estações. No entanto estes resultados são admissiveis em áreas estuarinas tropicais e subtropicais onde ocorrem fermentaçōes em quantidade para imporem elevaçōes temporárias do BOD.

A velocidade média das correntes em períodos de enchente e vazante mostra situações diferentes quando se compara os rios Jacuruna e Jaguaripe (Tab. III).

Nas estações do Rio Jacuruna a velocıdade média das correntes é maior na vazante, significando que as causas aqui geradas teriam os seus efeitos deslocados na direção do Canal; e como principal causa teríamos a considerar a drenagem de matéria orgânica detrital para as águas do rio nas épocas de intensa pluviosidade. No Rio Jaguaripe, observamos uma situação inversa com velocidade média maior na enchente, o que nos leva a admitir a pouca influência das águas interiores na estação 4 , fato confirmado pelas altas salinidades normalmente registradas e que situam esta estacão em condições semelhantes à estação $2 \mathrm{~A}$.

* Trabalho subsidiado pela Financiadora de Estudos e Projeto (FINEP). 


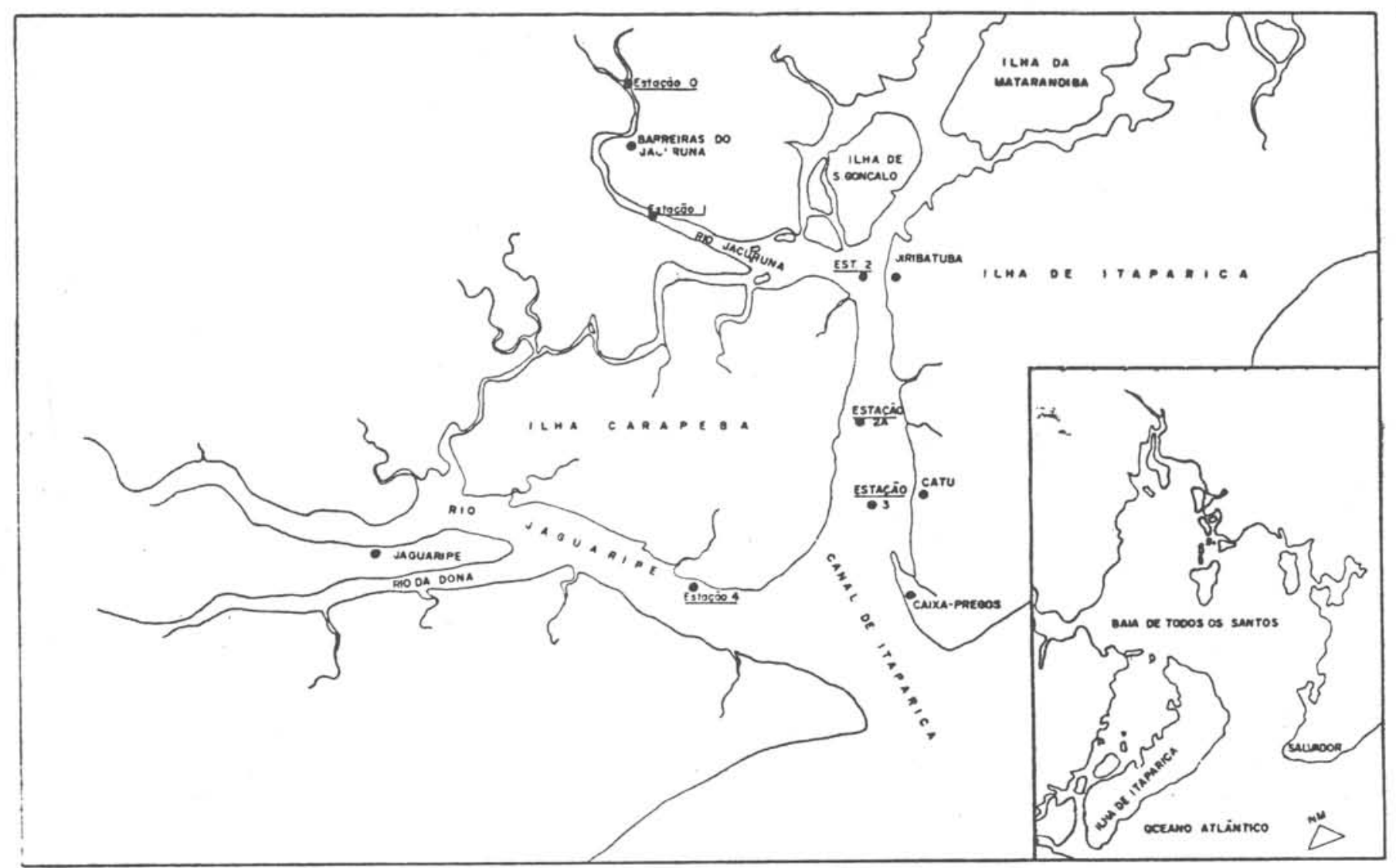

Fig. 1 - Estaçðes de amostragem

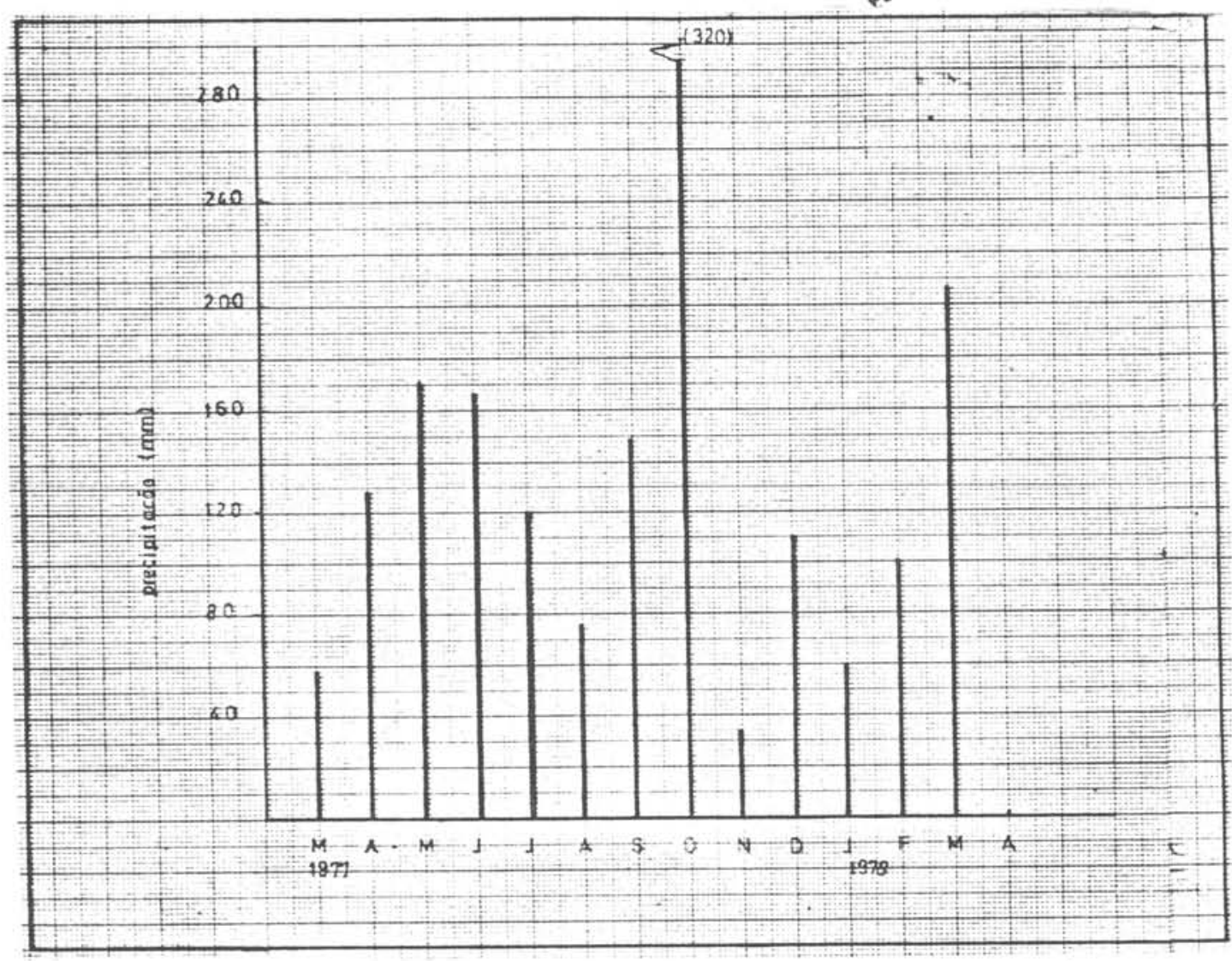

Fig. 2 - Est. 1 - Precipitação pluviométrica - totais mensạis 


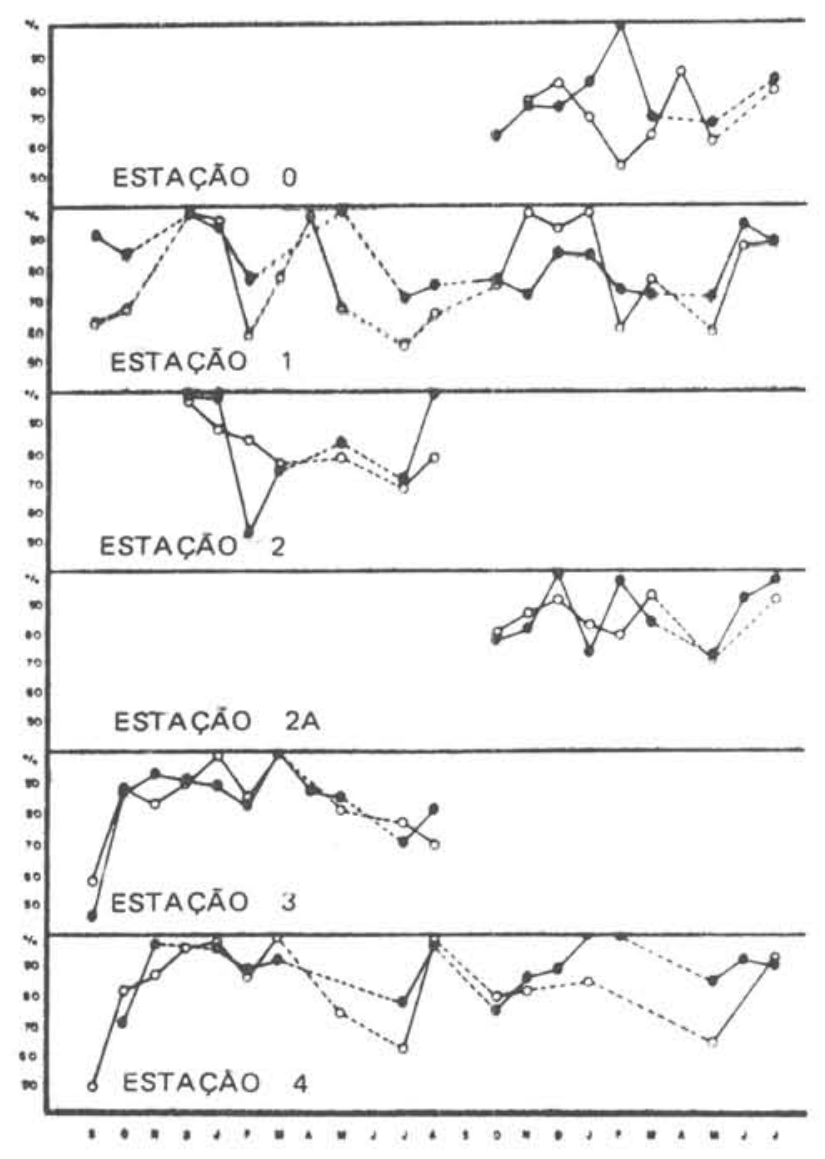

Fig. 3 - OXIGẼNIO, Setembro 76/Julho 77 Enchente $\bullet$

Vazante

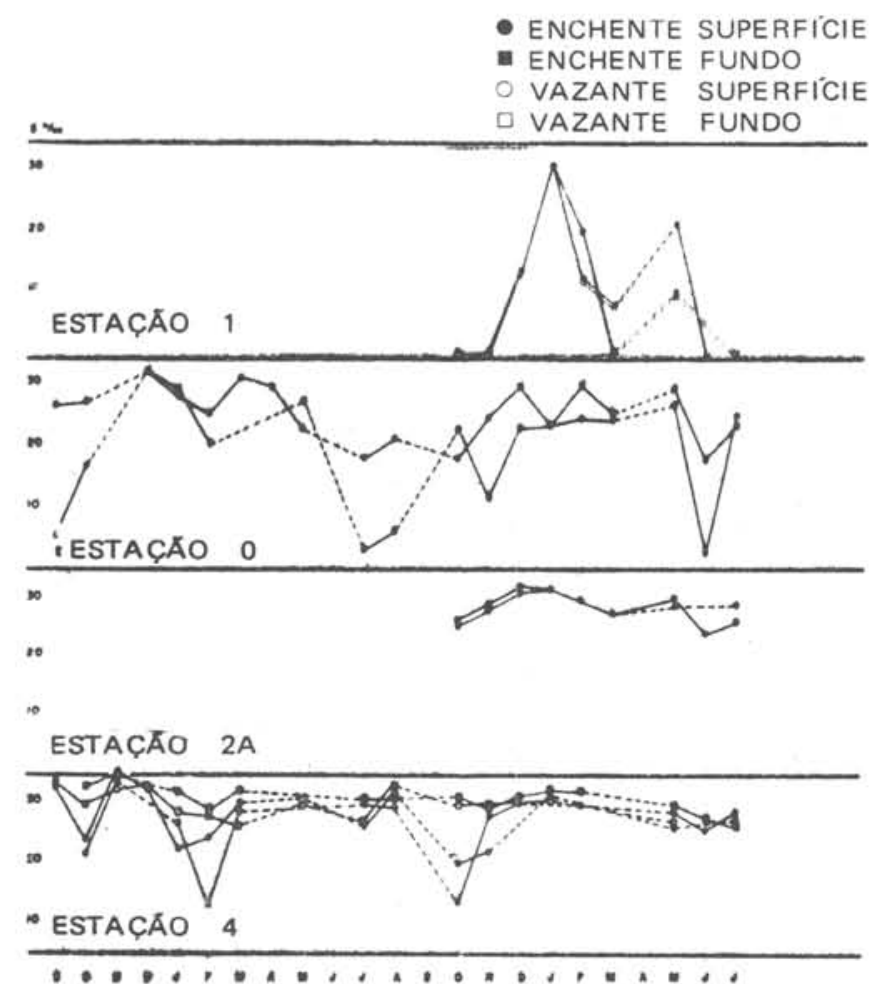

ENCHENTE SUPERFICIE

ENCHENTE FUNDO_-

VAZANTE SUPERFICIE.....

VAZANTE FUNDO_........

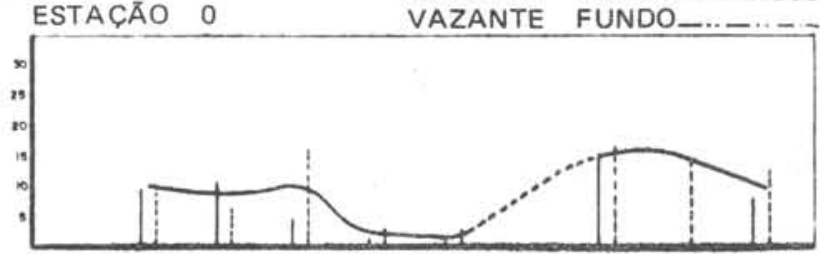

ESTACุÃO

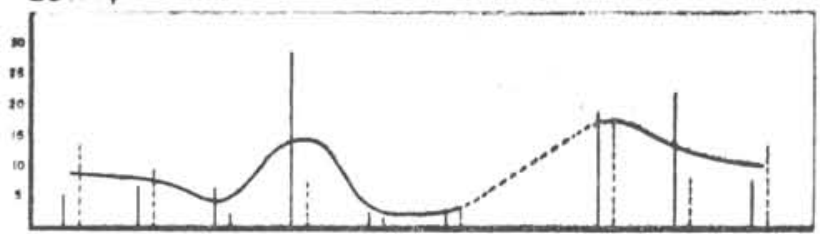

ESTAÇÃO $2 A$

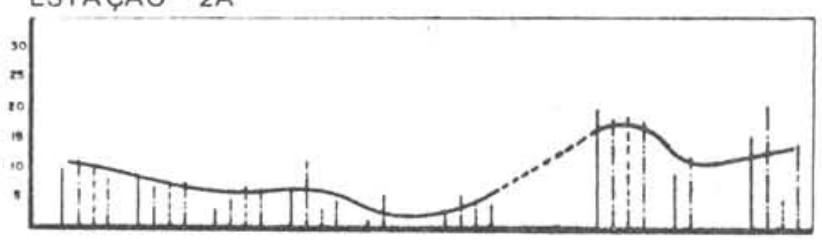

ESTAÇÃO 4

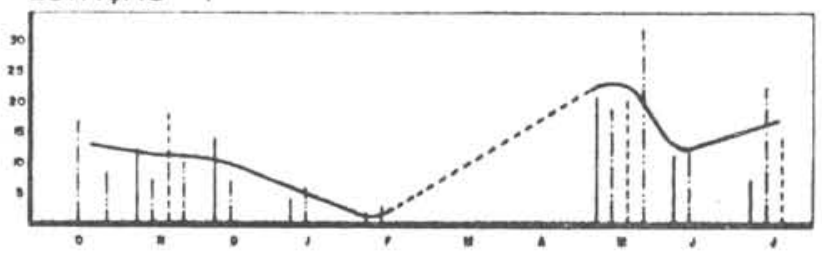

Fig. 5 - FOSFATOS, Outubro 77/Julho 78

ENCHENTE SUPERFICIE ENCHENTE FUNDO - - - -

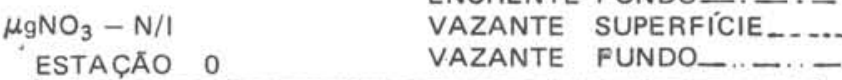
ESTACAOA
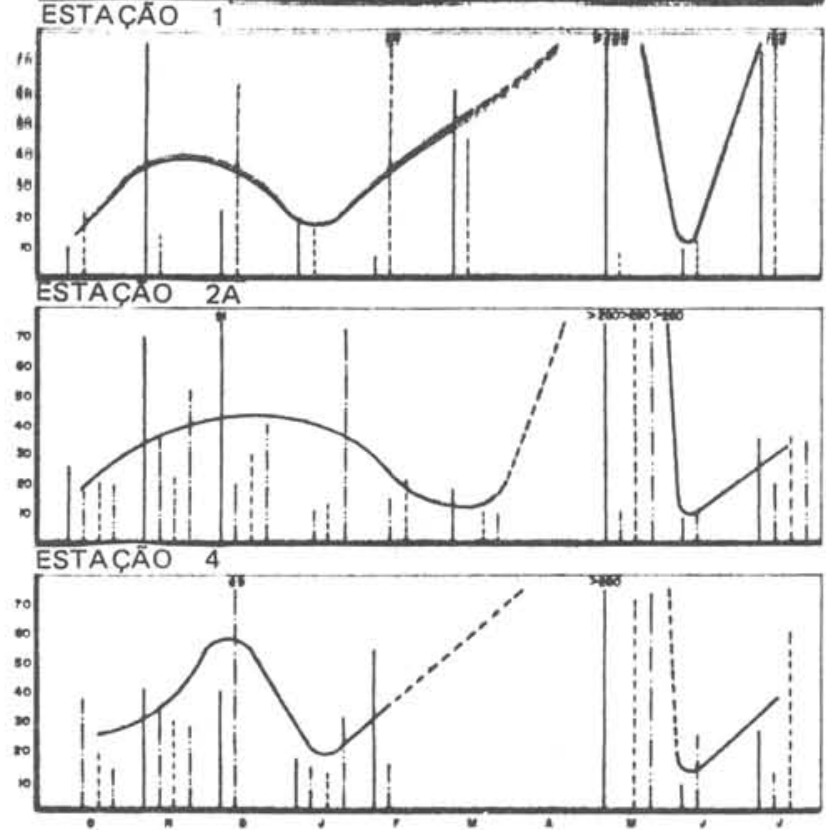

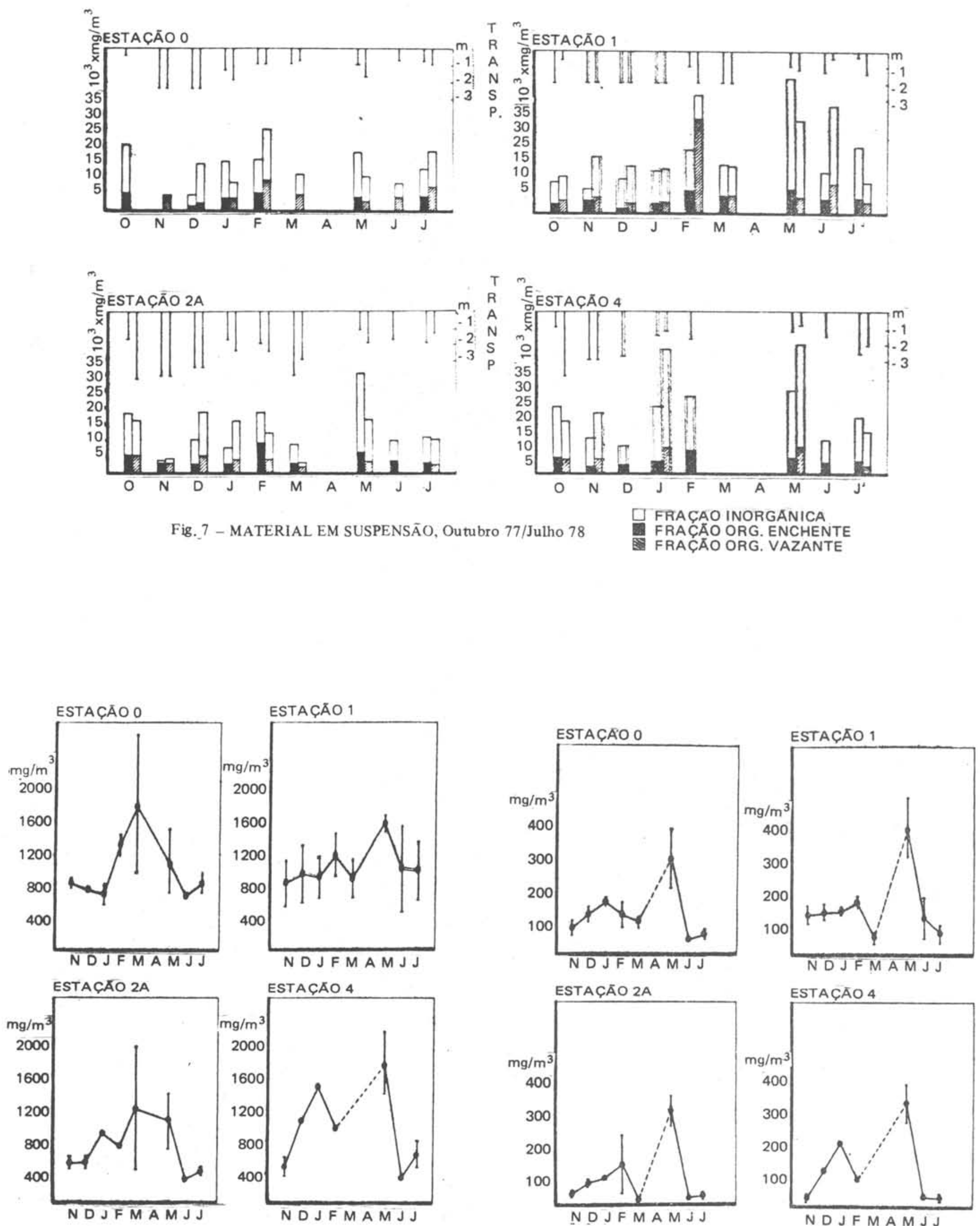

Fig. 8 - CARBONO PARTICULADO, Novembro 77/Julho 78

Fig. 9 - PROTEINAS, Novembro 77/Julho 78 
Tabela I - pH nas estaçøes de coleta

\begin{tabular}{|c|c|c|c|c|c|c|}
\hline MES & MARE & NIVEL & ESTACCÃO 0 & ESTAÇÃO 1 & ESTAÇÃO $2 \mathrm{~A}$ & ESTACÃO 4 \\
\hline \multirow[t]{4}{*}{ MARÇ } & \multirow[t]{2}{*}{ ENCHENTE } & SUPEREICIE & \multirow{2}{*}{6,1} & \multirow{2}{*}{7,9} & 8,1 & - \\
\hline & & FUNDO & & & 8,0 & - \\
\hline & \multirow{2}{*}{ VAZANTE } & SUPERFICIE & \multirow{2}{*}{6,9} & \multirow{2}{*}{7,7} & 8,2 & - \\
\hline & & FUNDO & & & 8,2 & - \\
\hline \multirow[t]{4}{*}{ MAIO } & \multirow[t]{2}{*}{ ENCHENTE } & SUPERFICIE & \multirow{2}{*}{7,3} & \multirow{2}{*}{8,0} & 8,1 & 8,0 \\
\hline & & FUNDO & & & 8,1 & 8,1 \\
\hline & \multirow[t]{2}{*}{ VAZANTE } & SUPERFICIE & \multirow[t]{2}{*}{7,9} & \multirow[t]{2}{*}{8,0} & 7,9 & 7,9 \\
\hline & & FUNDO & & & 8,0 & 8,0 \\
\hline \multirow[t]{4}{*}{ JUNHO } & \multirow[t]{2}{*}{ ENCHENTE } & SUPERFICIE & \multirow{2}{*}{-} & \multirow{2}{*}{8,0} & 8,1 & 8,0 \\
\hline & & FUNDO & & & 8,1 & 8,1 \\
\hline & \multirow[t]{2}{*}{ VAZANTE } & SUPERFICIE & \multirow{2}{*}{5,2} & \multirow{2}{*}{6,7} & - & - \\
\hline & & FUNDO & & & - & - \\
\hline \multirow[t]{4}{*}{ JULHO } & \multirow[t]{2}{*}{ ENCHENTE } & SUPERFICIE & \multirow[t]{2}{*}{5,9} & \multirow[t]{2}{*}{7,3} & 8,1 & 8,1 \\
\hline & & FUNDO & & & 8,1 & 8,0 \\
\hline & \multirow[t]{2}{*}{ VAZANTE } & SUPERFICIE & \multirow{2}{*}{5,6} & \multirow[t]{2}{*}{8,1} & 8,5 & 8,3 \\
\hline & & FUNDO & & & 8,4 & - \\
\hline
\end{tabular}

Tabela II - Temperatura nas estaç̃̃es de coleta

\begin{tabular}{|c|c|c|c|c|c|c|}
\hline MÊS & MARE & NIVEL & ESTAÇÃO 0 & ESTAÇÃO 1 & ESTAÇÃO 2A & ESTAÇÃO 4 \\
\hline OUTUBRO & ENCHENTE & $\begin{array}{l}\text { SUPERFICIE } \\
\text { FUNDO }\end{array}$ & 26.10 & 27.60 & $\frac{26,60}{26.50}$ & $\begin{array}{l}26.00 \\
26.80 \\
\end{array}$ \\
\hline 77 & VAZANTE & $\begin{array}{l}\text { SUPERFICIE } \\
\text { FUNDO } \\
\end{array}$ & - & 26.00 & $\begin{array}{l}27.20 \\
27.40 \\
\end{array}$ & $\begin{array}{l}27.20 \\
27.30 \\
\end{array}$ \\
\hline \multirow{2}{*}{$\begin{array}{c}\text { NOVEMBRO } \\
77\end{array}$} & ENCHENTE & $\begin{array}{l}\text { SUPERF ICIE } \\
\text { FUNDO }\end{array}$ & 26.50 & 31.10 & $\begin{array}{l}29.10 \\
28.60 \\
\end{array}$ & $\begin{array}{l}28.20 \\
28.00 \\
\end{array}$ \\
\hline & VAZANTE & $\begin{array}{l}\text { SUPERFICIE } \\
\text { FUNDO }\end{array}$ & 29.00 & 30.30 & $\begin{array}{l}29.00 \\
28.60 \\
\end{array}$ & $\begin{array}{l}30.00 \\
28.20 \\
\end{array}$ \\
\hline \multirow{2}{*}{$\begin{array}{c}\text { DEZEMBRO } \\
77\end{array}$} & ENCHENTE & $\begin{array}{l}\text { SUPERFICIE } \\
\text { FUNDO }\end{array}$ & 31.30 & 31.18 & $\begin{array}{l}29.00 \\
29.06 \\
\end{array}$ & $\begin{array}{l}29.02 \\
29.00 \\
\end{array}$ \\
\hline & VAZANTE & $\begin{array}{l}\text { SUPERFICIE } \\
\text { FUNDO }\end{array}$ & 32.70 & 31.70 & $\frac{30.20}{30.00}$ & $\frac{-}{-}$ \\
\hline JANEIRO & ENCHENTE & $\begin{array}{l}\text { SUPERFICIE } \\
\text { FUNDO }\end{array}$ & 28.44 & 29.60 & $\begin{array}{r}29.20 \\
29.00 \\
\end{array}$ & $\frac{-}{28.80}$ \\
\hline 78 & VAZANTE & $\begin{array}{l}\text { SUPERFICIE } \\
\text { FUNDO }\end{array}$ & 28.54 & 29.80 & $\begin{array}{l}29.11 \\
29.12 \\
\end{array}$ & $\begin{array}{l}28.60 \\
28.61 \\
\end{array}$ \\
\hline \multirow[t]{2}{*}{ FEVEREIRO } & ENCHENTE & $\begin{array}{l}\text { SUBERFICIE } \\
\text { FUNDO }\end{array}$ & 32.20 & 29.90 & $\begin{array}{l}29.30 \\
28.70 \\
\end{array}$ & $\frac{28.90}{28.30}$ \\
\hline & VAZANTE & $\begin{array}{l}\text { SUPERF ICIE } \\
\text { FUNDO }\end{array}$ & 28.40 & 29.10 & $\begin{array}{r}29.24 \\
29.40 \\
\end{array}$ & - \\
\hline MARÇO & ENCHENTE & $\begin{array}{l}\text { SUPERFICIE } \\
\text { FUNDO }\end{array}$ & 26.50 & 29.30 & $\frac{29.50}{29.50}$ & - \\
\hline
\end{tabular}


Tabela II (continuação)

\begin{tabular}{|c|c|c|c|c|c|c|}
\hline \multirow[t]{2}{*}{78} & \multirow[t]{2}{*}{ VAZANTE } & SUPERFICIE & \multirow{2}{*}{28.70} & \multirow{2}{*}{29.60} & 30.20 & - \\
\hline & & FUNDO & & & 29.80 & - \\
\hline \multirow{2}{*}{ MAIO } & \multirow{2}{*}{ ENCHENTE } & SUPERFICIE & \multirow{2}{*}{27.90} & \multirow{2}{*}{28.32} & 27.50 & - \\
\hline & & EUNDO & & & 27.44 & - \\
\hline \multirow[t]{2}{*}{78} & \multirow[t]{2}{*}{ VAZANTE } & SUPERFICIE & \multirow{2}{*}{26.10} & \multirow{2}{*}{26.90} & 27.80 & - \\
\hline & & FUNDO & & & 27.80 & - \\
\hline \multirow{2}{*}{ JUNHO } & \multirow{2}{*}{ ENCHENTE } & SUPERFICIE & \multirow{2}{*}{-} & \multirow{2}{*}{25.46} & 25.06 & 25.26 \\
\hline & & FUNDO & & & 25.38 & 25.42 \\
\hline \multirow[t]{2}{*}{78} & \multirow{2}{*}{ VAZANTE } & SUPERFICIE & \multirow{2}{*}{24.12} & \multirow{2}{*}{25.12} & - & - \\
\hline & & FUNDO & & & - & - \\
\hline \multirow{2}{*}{ JULHO } & \multirow{2}{*}{ ENCHENTE } & SUPERFICIE & \multirow{2}{*}{23.60} & \multirow{2}{*}{26.20} & 26.00 & 26.00 \\
\hline & & FUNDO & & & 26.00 & 25.80 \\
\hline \multirow{2}{*}{78} & \multirow[t]{2}{*}{ VAZANTE } & SUPERFICIE & \multirow{2}{*}{23.50} & \multirow{2}{*}{25.90} & 26.50 & 26.40 \\
\hline & & FUNDO & & & 26.40 & - \\
\hline
\end{tabular}

Tabela III - Direção e velocidade média de correntes de superfície

\begin{tabular}{|c|l|l|l|}
\hline \multirow{2}{*}{ ESTAÇÕES } & MARE & DIREÇÃO & $\begin{array}{l}\text { VELOCIDADE } \\
\text { MEDIA (m/h) }\end{array}$ \\
\hline \multirow{2}{*}{0} & ENCHENTE & $\mathrm{E} \rightarrow \mathrm{W}$ & 600 \\
\cline { 2 - 4 } & VAZANTE & $\mathrm{W} \rightarrow \mathrm{E}$ & 865 \\
\hline \multirow{2}{*}{1} & ENCHENTE & $\mathrm{E} \rightarrow \mathrm{W}$ & .666 \\
\cline { 2 - 5 } & VAZANTE & $\mathrm{W} \rightarrow \mathrm{E}$ & 1004 \\
\hline \multirow{2}{*}{$2 \mathrm{~A}$} & ENCHENTE & $\mathrm{S} \rightarrow \mathrm{N}$ & 1003 \\
\cline { 2 - 5 } & VAZANTE & $\mathrm{N} \rightarrow \mathrm{S} *$ & 1663 \\
\hline \multirow{2}{*}{4} & ENCHENTE & $\mathrm{E} \rightarrow \mathrm{W}$ & 1004 \\
\cline { 2 - 5 } & VAZANTE & $\mathrm{W} \rightarrow \mathrm{E}$ & 813 \\
\hline
\end{tabular}

- Para o cálculo de velocidade média da estação $2 \mathrm{~A}$ na vazante, utilizaram-se os dados de direção $\mathrm{N} \rightarrow \mathrm{S}$ por ser a direção que predomina durante a vazante; entretanto é comum verificar-se no Canal. uma inversão da corrente após a $3^{\mathrm{a}}$ hora da vazante para a direção $\mathrm{S} \rightarrow \mathrm{N}$. 
Dos macronutrientes analizados, as concentraçōes de amônia apresentaram grandes flutuações sazonais, entre-marés e mesmo entre superfícies e fundo, com valores minimos em todas as estações no mês de novembro $(0,3 \mu \mathrm{g} / 1)$ e máximos em fevereiro quando chegaram a ultrapassar o limite de deteç̧ão do método $(84 \mu \mathrm{g} / 1)$; entretanto, situaram-se sempre dentro dos limites considerados normais para águas não poluídas e bem oxigenadas. As concentrações de nitritos são sempre baixas com pequena amplitude de variacão sazonal e valores máximos registrados no mês de maio $(9 \mu \mathrm{g} / 1)$.) Os silicatos apresentaram grandes flutuaçōes sazonais e concentrações relativamente altas, frequentemente uitrapassando o limite de detecção do método $(40 \mu \mathrm{g}$-at $/ 1)$.

As concentrações de $\mathrm{P}_{-} \mathrm{PO}_{4}$ (Fig. 5), evidenciam uma nítida variação sazonal com um esgotamento visivel em todas as estações nos meses de fevereiro e março, fim do período de estiagem, o que sugere ter este elemento uma origem principalmente terrígena; uma elevação na concentração dos fosfatos imediatamente após o início do período de chuvas, com picos em majo (valores máximos de $32,5 \mu \mathrm{g} / 1$ ), confirmam esta hipótese. Apesar das variações sazonais, as médias anuais das concentraçōes de fosfatos mantém-se equilibradas nas estacôes 0,1 e $2 \mathrm{~A}$ com valores de aproximadamente $9,0 \mu \mathrm{g} / 1$. Já na estação 4 esse valor médio sobe para $12,7 \mu \mathrm{g} / 1$, onde é possível haver uma contribuição devido à drenagem de fertilizantes em áreas cultivadas que margeiam o Rio Jaguaripe.

Com relação aos nitratos (Fig. 6), a variação sazona acompanha em valores médios o que foi observado para os fosfatos, embora com flutuações bem maiores entre-marés e entre superfície e fundo. Também aqui, a carência maior é observada no fum do período de estiagem correspondente aos meses de janeiro, fevereiro e março e picos que ultrapassaram o limite de detecção do método $(280 \mu \mathrm{g} / 1)$ foram detectados no més de maio. As medidas anuais mostraram um gradiente crescente da estação 0 para a estaçāo $4 \mathrm{com}$ valores de 42,9 (est. 0 ) - 51,6 (est. 1) - 52,1 (est. 2A) - 54,0 (est. 4). Esse gradiente, observado apenas para os nitratos, talvez se explique pelas diferenças de velocidade nos fluxos de enchente e vazante no Rio Jacuruna; uma vez que a mineralização do $N$ é mais lenta que a do $P$, a causa gerada no Jacuruna teria o seu efeito deslocado para o Canal.

As relações $\mathrm{N}-\mathrm{NO}_{3} / \mathrm{P}-\mathrm{PO}_{4}$ inorgânicos calculadas a partir desses dados e que se situa entre 10 e 20 em águas costeiras não poluídas, apresentou grandes flutuações, apesar da correspondência sazonal entre curvas médias de nitratos e fosfatos; algumas vezes foram observados valores de 1,4 e mesmo $<1$ ก (maio e junho), isto é, concentraçōes de fosfatos mais elevadas que as de nitratos. $\mathrm{Na}$ estação $2 \mathrm{~A}$, onde essa relação se manteve menos instável no decorrer do ano, foram registradas variaçōes de 1 a 17. As mais altas relações foram observadas no mês de fevereiro, com valores de 57 na estação 1 e 89 na estação 4 .

A matéria em suspensão analizada gravimetricamente e decomposta em fração orgànica e inorgânica, mostra na Figura 7 uma relação com a transparência, evidenciando o papel das chuvas no transporte de material particulado terrígeno para as águas, reduzindo a transparência; o seston mostra-se ligeiramente mais relevante na estação 1 .

A biomassa do seston avaliada em termos de carbono particulado (Fig. 8) mostra uma nitida variação estacional, com picos excepcionais mais ou menos coincidentes, no período compreendido entre fevereiro e maio, determinando esse período como o mais favorável em termos de alimento disponível quantitativamente para os consumidores primários. Vale ressaitar as grandes flutuaçōes observadas entre-marés e que esses dados estimam a matéria orgânica particulada total viva e não viva, incluindo, portanto, além de fito e zooplâncton, bactérias e detritos orgânicos em diferentes estágios de decomposição.

Em termos de proteinas (Fig. 9), esta biomassa mostra estreita correspondência com os dados de carbono quanto à variação sazonal, com os valores médios de enchente e vazante mostrando desvios menores e picos no mês de maio nas 4 estações.

\section{Discussão}

A produtividade biológica em ambiente aquáticos é principalmente função de organismos planctônicos que constituem a basa energética para a existência de outros níveis tróficos, inclusive peixes. Entretanto, a matéria orgânica em suspensão na água do mar tem 4 componentes principais: fitoplâncton, zooplâncton, bactérias e detritos, estes últimos resultantes da destruição de organismos mortos de origem animal e vegetal (Finenko \& Zaika, 1973).
Em áreas estuarinas marginadas por manguesais, devido à grande contribuição da vegetação arbórea, esses detritos podem representar até $80 \%$ da biomassa sestônica total, desempenhando um relevante papel na alimentação de animais filltradores.

$\mathrm{Na}$ área em estudo, ficou comprovada a importância quantitativa dessa matéria detrítica como componente da matéria particulada em suspensão, e o papel desempenhado pelas chuvas no carreamento desses detritos.

Finenko \& Zaika (1973) referem para o Azov Sea grandes quantidades de matéria orgânica particulada, chegando a atingir no verão $1500 \mathrm{mgC} / \mathrm{m}^{3} \mathrm{e}$ atribuem esse fato à intensa descarga de rios. No rio Jacuruna encontramos concentraçōes de carbo no de até $2600 \mathrm{mg} / \mathrm{m}^{3}$ no início do período de chuvas. As proteínas totais do seston acompanham a curva de variação sazonal observada para o carbono, com picos em todas as estaçōes no mês de maio. Nesse período, o seston tem um teor proteico de 25 a $30 \%$ o que parece conferir ao mesmo uma melhor "qualidade" como alimento para animais filtradores.

Brito \& Simas (em publicação) encontraram nessa área uma baixa densidade celular para fitoplâncton, com um valor médio inferior a $1 \times 10^{6}$ células/litro, evidenciando que o mesmo não assume na área um papel de relevo. Paredes et al. (em publicação) confirmam que a taxa fotossintética com uma produtividade média de $45 \mathrm{grC} / \mathrm{m}^{3} / \mathrm{ano}$, não coloca esta área como privilegiada no concernente à produção com origem no fitoplâncton, sendo o nitrogênio o fator que mais parece atuar como limitante da produção primária.

Embora os nitratos e fosfatos apresentem altas concentraçōes nos periodos de chuvas, as grandes flutuações na relação $\mathrm{N} / \mathrm{P}$ podem ser altamente desfavoráveis à produção do fitoplâncton.

As grandes flutuaçōes entre-marés observadas na maioria dos parảmetros analizados dificulta a interpretacão dos dados, sugerindo não ser a metodologia de amostragem utilizarla a mais conveniente para esse tipo de trabalho. Em continuidade serão realizadas monitoragens de 24 horas que permitirão melhor acompanhar as variações diumas no decorrer do fluxo e refluxo das marés; também a introdução de análises de clorofila a ativa e feo pigmentos permitirá urna avaliação da real contribuição do fitoplâncton e da matéria detrítica de origem vegetal para a matéria orgânica particulada.

\section{Agradecimentos}

Os autores desejam expressar seus agradecimentos aos biólogos Welton Rocha, Mara do Carmo Soares e Ronan C. Brito, pela valiosa colaboração nos trabalhos de campo e laboratório e na confecção de gráficos.

\section{Bibliografia}

BRITO, R.R. C. \& SIMAS, E.M.P. Variação sazonal do fitoplâncton na área estuarina SW da Baía de Todos os Santos. (no prelo).

FINENKO, Z. Z. \& ZAIKA, V. E. 1973. Particulate organic matter and its role in the productivity of the sea. In: Steele, J. H. ed. - Marine food chains. Edinburgh, Oliver \& Boyd, v. 2 p. $32-44$.

GRASSHOF, K. 1976. Methods of seawater analysis. New York, Verlag Chemie, $317 \mathrm{p}$

MAGLIOCCA, A. 1966. Manual sobre métodos de rotina para a determinação de elementos químicos dissolvidos na água do mar. São Paulo, Instituto Oceanográfico, 35 p. (mimeo grafado).

PAREDES, J. F.; PEIXINHO, V. M. C. \& BRITO, R. R. C. Produtividade primária, biomassa e fatores limitantes na área estuarina SW da Baía de Todos os Santos. (no prelo).

PERKINS, E. J. 1974. The biology of estuarines and coastal waters. London, Academic Press, 687 p.

PRICE, C. A. 1965. A membrane method for determination of total protein in dilute algal suspensions. Analyt. Biochem. 12:213-218.

STRICKLAND, J. D. H. \& PARSONS, T. R. 1972. A practical handbook of seawater analysis. 2nd ed. Bull. Fish. Res. Bd Can., (167): 1-311. 